\title{
特別講演 2
}

\section{The Reception of Oriental Medicine in the West}

\author{
- Changing World View and Epistemological Adaptation -
}

\author{
Paul U. Unschuld
}

First reports of distinctly Far Eastern medical practices appear to have reached Europe in the 16 th century. This initial period was marked by the translation of texts on acupuncture and pulse diagnosis, and by reports of interesting clinical practices witnessed by these men in the Far East.

It was only during a second phase (beginning in the second half of the 18th century and lasting until the middle of the 19th century) that a very widespread interest emerged in Europe in the possibilities of a clinical application of acupuncture, moxibustion, and pulse diagnosis.

From today's perspective, the reasons why acupuncture was unable to take hold in $\mathrm{Eu}$ ropean health care at that time, and why Chinese medicine remained almost forgotten in Europe for one hundred years from the middle of the 19th century until the middle of the 20th century, represent a most fascinating research issue. In my lecture today, I shall attempt to provide some answers based on my research in previous years.

It is obvious from the writings of Andreas Cleyer, and from those of his contemporaries and subsequent authors, that 17 th and 18th century Europeans approached Chinese medicine open-mindedly. Following the Renaissance, an endless stream of new findings in anatomy and physiology had increasingly challenged the old Galenic system, and European medicine of the time moved into many directions.

There was no reason for European physicians to exclude foreign cultures from their search for better health care practices and concepts, and it was only natural that a general curiosity was extended to the Far East. After all, numerous European physicians and naturalists (affiliated either with Christian missions, with trading companies, or with government embassies) lived in the Far East and reported their observations of medical practices from there.

In Cleyer's Specimen of 1682 we encounter a first serious attempt to publicize in Europe not only the facts of the practice and of the effects of needling in East Asia, but also the theoretical background attributed to them by the Chinese.

Cleyer spoke of the conduit system, and he translated the Chinese term 経 ("conduit") with the Latin via ("path", "way"). He discussed the Chinese idea of qi (気), and he

M. D., Prof. of the Research Center for Medical History, Univ. of München, Deutchland 
rendered this complex and complicated term with an equally complex and complicated, and-at the time-most appropriate European term, i. e., "spiritus". Nevertheless, it is evident from Cleyer's book that he had not gained a deep or sufficient understanding of Chinese medical theory.

This is not surprising given the state of the art in China at that time. Obviously, the practice and theoretical background of acupuncture had fallen into near oblivion in China itself exactly by the time when the European interest was evoked.

$\mathrm{Xu}$ Dachun 徐大椿 (1693-1771) offers in his Survey of the History of Chinese Medicine (医学源流論) of 1757 a most interesting description of the situation of acupuncture in China at his time, stating that acupuncture had become a lost art, for there were then left very few experts in it. The extreme of this decline of the art was reached in 1822, when an edict forbade the teaching of acupuncture in the Imperial Medical College, the Tai-yi-yuan 太医院.

That is, when Europeans in larger numbers began to focus their eyes on Chinese medicine, the situation in China had deteriorated to a point where, if we believe $\mathrm{Xu}$ Dachun, not even Chinese physicians interested in studying acupuncture were able to find a knowledgable teacher. Given, in addition, the general attitude of the Chinese towards foreigners, one may wonder how in such a situation Europeans should have gained access to the subtleties of acupuncture that had been discussed in Chinese medical literature centuries ago but had given way to crude folk practices of needling in the mean- time?

From this perspective it may be worthwhile to take a look at the writings of an early 19 th century Italian physician actively involved in the investigation of acupuncture, Dr. Francesco Da Camino (1786-1864).

How much did Francesco Da Camino know of the ideas and practices developed around the technique of needling in the Far East? It was a matter of deep concern to $\mathrm{Da} \mathrm{Ca}$ mino that the practice of acupuncture seemed so simple. He pointed out, in 1838 already, that this apparent "simplicity" carried the risk of careless application: "The therapeutic effects of such an easily applicable operation are so surprising that it seems the ignorant and the lazy could think they held in their hands the entire art of medicine, 'safe, fast, and enjoyable' as Hippocrates described it."

Drawing attention to East Asian knowledge published in the writings of European authors and verified by the experiences of European physicians, Da Camino related to his readers certain empirical rules thought to prevent harm in the application of acupuncture. He emphasized that the needles should never be applied at the time of major physiological processes, the most important of these being digestion. Also, persons whose mind or emotions are "overly excited," those who may just develop a dangerous disease, and those covered with sweat, should not be submitted to acupuncture. Da Camino demanded that the muscles of the patient's entire body, and especially of the location to be needled, should be relaxed, and that the patient should be informed of the negative consequences that may follow an inadvertent movement. Per- 
haps he had read such accounts as publicized in 1825 by Recamiers from the Hôtel-Dieu in Paris where a patient who had three needles inserted into his abdominal wall died after he had decided-against the warnings of his physician-to go to the toilet. Two needles near his navel had simply vanished into the abdomen.

In this context Da Camino wrote: "One should not be surprised that the same Japanese, who do not hesitate to needle a fetus in the uterus of its mother, refrain from the application of acupuncture for reasons that have no basis other than meteorological changes, such as heavy rain, strong storms, or earthquakes."

One aspect of Chinese acupuncture met little understanding in Europe, that is the needling of locations far away on the surface of the body from a painful area to be treated.

Da Camino stated: "In my opinion, the tip (of the needle) is to be inserted into the affected tissue immediately or at least very near to it. The Chinese are used to needle in considerable distance of a painful location, and they claim that there exist connections between this distant point of insertion and the diseased point. My own practice, however, does not allow me sufficient insight into this."

Thirteen years after the publication of his 1834 essay focussing on the practical aspects of acupuncture therapy, Da Camino laid before his peers a second essay devoted, almost entirely, to a discussion of what he called a "theory of acupuncture."

If we had expected to find in this essay a detailed discourse spreading out an East Asian rationale of acupuncture in front of European readers, one would be disappointed. Still, the few remarks Da Camino made on Asian viewpoints are not at all marked by presumption. Even as late as 1847, it seems, physicians like Da Camino, firmly based in the emerging sciences of Europe, were still open-minded enough to consider Asian perspectives with genuine interest.

Da Camino had been interested, he informs his readers, in a scientific explanation of acupuncture ever since he had begun to practice it. How is it possible, he wondered, to cause such rapid changes, as can be observed in the application of acupuncture, in the human organism with the insertion of a single needle. Perhaps, he wrote, it is even possible to discover the origins of pain through this unfamiliar therapy.

Based on the reasoning of previous authors and on his own conclusions, Da Camino proposed the existence of an electrical fluid as responsible for disturbing the normal state of certain tissues or of the entire organism. Human and animal experiments with electricity had demonstrated, Da Camino wrote, the movement of electric currents through the nervous system. The dissipation of pain and other pathological conditions through needling employed the same mechanism, in perfect imitation of nature.

I cannot go into more detail here concerning the work of Da Camino. I have selected Da Camino as one typical representative of many European writers at the time, so as to demonstrate that acupuncture was widely known, tested, and discussed in the 18th and 
early 19 century. I wish to repeat here the question I had raised earlier in my lecture already: why is it that acupuncture, in contrast to the second half of the 20th century, did not rise to any noteworthy position in European health care in the first half of the 19 th century, and, why did it fall into disregard again?

To explain this phenomenon it could be pointed out, first, that acupuncture during the 18th and 19th century, in contrast to the attention devoted to it in China in the mid20 th century, had fallen into disrepute in China itself; second, that acupuncture in the 18th and 19th century, again in contrast to the current situation, received no political backing by the Chinese government, and third that no economic interest on the side of Chinese teaching institutions or individuals existed to emphasize the value of needling and to sell this technique internationally by inviting foreigners to study it in exchange for hard currency.

Still, these differences between the situation nowadays and the situation in the late 18th and early 19th century may explain some aspects of the resurgent European interest in acupuncture since the 1960 s, but they cannot account for the problems acupuncture had to prove its value one hundred fifty years ago.

Perhaps one should search at deeper layers in the history of ideas for an explanation of the fate of acupuncture in Europe in the 19th century. It is at this point that we must ask ourselves why therapeutic practices and theories are accepted in a population.

Looking back at the past two thousand years, it is quite obvious that throughout history populations have accepted therapeutic systems because their theoretical basis appeared convincing. We have no evidence that therapeutic systems have been accepted by populations because of superior clinical successes. Why, then, we may ask further, is a theoretical basis convincing? Again, two thousand years of medical history in the West and in the Occident make it quite clear that a theory of the nature and appropriate treatment of illness is convincing to a population when it parallels the notions, held by the same population, concerning the nature and appropriate management of social crisis. In other words, all known societies have explained crisis and crisis management inside the human organism in the same way as they have explained crisis and crisis management in society.

If within one civilisation different social strata exist holding different ideas concerning the nature of social crisis and how best to prevent or treat it, then we will find different therapeutic systems within that civilisation. For instance, the world views of the peasant population in China differed from the world view of the educated Confucian elite. As a result, the views on health and illness differed between these social strata too.

Whereas a Confucian scholar lived in an environment where social wellbeing appeared guaranteed if one adhered to a detailed set of rites and rules, a Chinese peasant lived in a very different environment. A peasant rarely could be convinced that the future was predictable, and depended on an adherence to specific rules. A peasant could toil as hard as possible, but the fruits of his work could 
be taken away from him without warning either through natural catastrophies or by the impact of a corrupt bureaucracy.

Hence it is understandable that the Confucian elite "believed" in a medicine which promised health as long as a person adhered to a detailed set of rules concerning food, clothing, resting and working, etc. The rural population, in contrast, "believed" in a medicine which promised health as long as a person guarded him/herself against unforeseeable catastrophies caused by invisible forces, i. e., demons. It is not because of differences in intelligence that the rural population in China preferred, until the 20th century, a health care based on demonological notions. The reason that the medicine of yinyang and five phases remained largely restricted to the educated elite may be found in the fact that notions of yinyang and five phases regularities appeared plausible and convincing only to the elite because their entire social life was characterized by regularity too.

Let us return to the acceptance of acupuncture in Europe in the 18th and 19th century.

It is obvious that acupuncture entered Europe as a therapeutic technique without a sufficient theoretical context. European phy sicians and other travellers who observed Oriental medical practice in the Far East had no time to study ancient literary sources on the theoretical background. Also, in Europe there was no tradition of East Asian studies yet which could have offered an explanation of what the European travellers had seen in China, Japan, and Batavia. Hence there was no theory available that could have predis - posed the minds of researchers and users to believe that successes achieved with acupuncture were proof of the "truth" of that theory.

Acupuncture was applied against a wide range of functional illnesses, sometimes with good results and often without positive results. No theory existed to emphasize the good results, and downplay the failures. The theoretical framework chosen by European physicians to explain the effects of needling, that is stimulation of an electro-nervous fluid, was not sufficiently grounded in any largescale social theory. Hence when the interest in electric explanations of physiology faded in European medical science in the course of the 19th century, the interest in acupuncture faded too.

Failures in the application of acupuncture were seen now as proof that it was worth nothing. The many successes achieved with acupuncture by European physicians, and recorded by Da Camino in Italy, Berlioz in France and by other clinicians, assumed nothing but anecdotal value because of the lack of a convincing theory.

Here we turn to the middle of the 20th century, and again we ask ourselves: why, after a period of dormancy for one hundred years, has Oriental medicine become so attractive to an ever increasing part of the population in Western countries?

Once again and in contrast to what we may have assumed until now, I should like to emphasize that it is not the clinical success of a therapeutic system that is responsible for its acceptance in a population. Rather it is the plausibility of the theory that is respon- 
sible for an interpretation of clinical successes as effects of that therapeutic system.

Since the 1970s we have witnessed a steady increase in interest in Europe and the United States into Oriental Medicine. It would be difficult to find even small or middle sized cities where there is no therapist offering acupuncture, moxibustion, qi gong, or other Oriental therapeutic interventions. Countless schools of Oriental medicine have been founded in Europe and in the USA to teach physicians and other health care personnel in the techniques of Oriental Medicine, but also in the theory that is behind it. Medical bookshops and also general bookstores stock large quantities of books written by Asians, Europeans, and Americans on the theoretical background as well as on diagnostic and therapeutic applications of Oriental Medicine.

What, we should ask, is so different in com parison with the situation 150 to 200 years ago?

Several developments have occurred in the meantime.

First, the Western world and Japan have contributed to a breathtaking development of science and technology. There is hardly any aspect of daily life which has remained untouched by science and technology. For about one hundred years the population of Europe, the USA, and Japan has been fascinated by the promises of chemistry, physics, and technology. Whether it is a microwave oven in our kitchen or a rocket on the moon, we have witnessed a most impressive dynamics in the application of scientific findings to human life.
However, for the past two or three decades an increasing segment of the population in Europe and in the USA has also opened its eyes to see the price of these dynamics. Chemistry has given mankind vast possibilities of generating new substances, new colors, new sources of food, new pharmaceutical drugs. Nowadays, however, chemistry is increasingly seen not only as a beneficiant science, but also as a threat to our environment and hence to our life. Catastrophies such as have happened in Bhopal and Seveso add fuel to a general awareness that our food, the air we breathe, and the water we drink are contaminated to an ever increasing degree world wide.

Technology has given us an unprecedented mobility by car, by train, by ship, and by air planes. We benefit from voice and vision telecommunication systems that even a hundred years ago no one would have dared to dream of. Still, as in the case of chemistry, the image of technology has been stained in the eyes of a growing segment of the population in Europa and in the USA. Technology, as they see it, is also responsible for the destruction of our environment. More and more highways are built and destroy beautiful landscapes. Modern industry spoil hitherto untouched regions. Airplanes and cars pollute the air with toxic fumes. Atomic energy may kill us all either through nuclear weapons or through catastrophies such as occurred in Tchernobyl.

With these negative connotations in mind, not only the value of chemistry and technology is reassessedn; Western medicine, too, is no longer seen as solely beneficial. Just as a growing number of people fear that chemicals 
pollute our environment, a growing number of people fear that chemotherapy pollutes our personal organism. Chemotherapy, once hailed as a solution to many health care problems, is regarded by a segment of the population in Western countries now as causing health care problems itself.

The same applies to technology. X-rays, computer tomography, and many other developments appear as miraculous signs of medical progress to the majority of the medical community. But there are other voices too. They complain that in Western medicine no longer the physician examines and "takes care of" the patient. Rather these people see themselves examined by "machines", by "cold tech nology" which then, in turn, "speaks" to the physicians by means of data appearing on screens or in print-outs.

It is at this point that we begin to under stand why Oriental Medicine has become so attractive in the West. Those people whose existential fears are nourished by the increasing impact of chemistry and technology on daily life, they welcome a medicine which appears not to rely on chemical substances and technological means of diagnosis and treatment. Oriental Medicine is propagated as a therapeutic system relying on "natural" substances, without side effects. Those people in the West who fear in increasing pollution of their bodies through chemistry in food, water, and air, they are happy to have found in Oriental Medicine a therapy system the application of which does not entail the risk of chemical pollution. Similarly, those people in the West who have an aversion to what they regard as "cold" and "impersonal" technology, they are happy to have found a ther- apy system where diagnosis and treatment entail direct contact with the healer. There is nothing between healer and patient when the former feels the pulse or palpates the abdomen.

Also, a patient with various symptoms going to a hospital of Western medicine may be examined by representatives of various specialties; he/she may be sent to a cardiologist, to a rheumatologist, to an orthopedist, and to a surgeon, and each of these specialists may offer his/her view on the patient's problem. The patient may even leave the hospital with two or three prescriptions of different medications for "different" problems that were diagnosed. If we look at Western societies with their increasing individualism, we will discover that this increasing individualism has been achieved at the price of an increasing pluralism. A consequence of social pluralism, however, is a development towards increasing fragmentation not only of society but also of world views. There is a lack, in Western societies, of a central world view offering a convincing existential interpretation to the population. Rather, everyone develops his or her own world view on minor issues, with the result that the central meaning of our existence appears to have been lost.

While a majority of people in the West still welcomes this development as a development towards greater individual freedom, a growing segment of the population feels uneasy and complains about the lack of a central meaning guiding our understanding of human existence. Such complaints are nourished by organisations such as the various religions who offer such a "central meaning" and who offer ready-made answers to those 
who are at a loss when they see all the problems facing the world in the presence and in the future.

Western medicine is fragmented into many specialties and sub-specialties, and, as we all know, a patient may leave a hospital without "knowing" the central issue or meaning of his/her illness. In contrast, Oriental Medicine always has an explanation at hand when a patient is diagnosed. One central problem is the source of symptoms which, in the understanding of Western medicine, fall into the realms of different specialties and have to be treated by different specialists. In Oriental Medicine, in contrast, one treatment is advocated to eliminate the central problem and, as a result, to eliminate the various symptoms resulting from this central problem. Europeans and Americans in search of the "central meaning" in life are happy to have found in Oriental Medicine a therapeutic system which offers a "central meaning" at least when it comes to personal illness.

There is yet another major reason for the attractiveness of Oriental Medicine in Europe and in North America. Popular accounts in Western mass medica of recent findings in immunology and virology are often worded in military language. We read of "biological warfare" in the organism, with "killer cells hunting the enemy", with "hostile intruders being bombarded by antibodies", etc. Many more examples could be cited. Now, it has always been the case that metaphorical language has been found helpful in medicine to explain difficult physiological processes to the general public. Also, military language has been used in Western medicine ever since the rise of bacteriology, i. e., ever since dis- eases were identified as "real enemies" in the form of bacteria or virusses. These enemies had to be fought, eliminated, killed. In Chinese medicine, military language dates back much further to the very origins of Chinese medical theory. The use of drugs has of ten been compared, in Chinese medical history, with the use use of soldiers. It is a common topic in Chinese medicine that the "evil", the "bad" (邪) is fought by the "proper", by the “virtuous" (正).

In modern accounts of Oriental Medicine, this militaristic tradition is rarely mentioned. Rather, Oriental Medicine is presented to the Western public as a therapy system seeking to maintain or re-establish harmony within the individual organism, and to maintain or re-establish harmony between the individual organism and a larger macrocosm. A certain segment of Western populations is extremely concerned about what they see as a continuing belligerence in the world. From the Vietnam war to the Gulf war, from the campaigns in Latin America to the civil war in former Yugoslavia, there seems to be an unending series of atrocities in the world. Those who consider these wars as increasingly disgusting are people longing for peace and harmony.

When they look at the latest advances in modern immunology and virology, they are faced with a vision that, in case of illness, they have to unleash a war in their own organism with all the consequences a war entails: killing, injuries, victims. Oriental Medicine, as it is portrayed in modern writings, offers a different program. Illness is described as a temporary loss of harmony, and treatment seeks to restore this harmony. This is 
what war-tired people in the West would like to see at a time when they are ill and need help: not another war, but a vision of harmony.

And there is one final aspect that must be considered when we wish to understand why Oriental Medicine is so attractive to many Westerners today. For the past twenty or thirty years, one of the most threatening issues in world politics and in the internal politics of all Western countries has been the issue of energy. Ever since the first energy crisis in the 1970s, the question of energy supply has been a key issue in international politics. Western countries have fought wars because of the energy. In internal politics the energy issue has been equally critical. Some Western countries have had strong opposition to a further development of nuclear energy; there have been endless clashes between security forces and demonstrators against new power plants. The prices of energy have continually risen since the seventies, and this has had an impact not only on domestic industry and trade, but also on most people's very private household planning. Electricity is expensive nowadays, and so is gasoline to drive a car. The possibility that energy supplies are cut off is as threatening as an interruption of food supply.

It is most interesting in this regard that the Chinese term qi 気 is translated, in most texts on Oriental Medicine, into Western languages as "energy". This is, of course, very different from its historical meaning in ancient Chinese sources. Nevertheless, a translation of qi as "energy" adds to the attractiveness of Oriental Medicine. Oriental Medicine is presented in the West as a therapeutic system which promises to solve the qi problems, i. e., "energy" problems - at least of a patient's individual body. This interpretation of qi is entirely based on Western thoughts and aspirations; it serves to give Oriental Medicine that plausibility which I have outlined as needed by a therapy system to be accepted in a population.

The translation of qi as "energy" is not the only evidence of an adaptation of Oriental Medicine to Western culture. In comparison with historical Chinese medicine, contemporary accounts of Oriental Medicine do not contain those of its traditional facets that might be considered contradictory, obsolete, metaphysical, or absurd by Western audiences. Also, translations of traditional Chinese medical terms into Western languages are rarely literal. On the contrary, translators tend to avoid literal translations of certain key terms, for instance of 蔵, or 府, in order to avoid an "unscientific image".

What I have outlined in the past few minutes may be sufficient to give credence to my earlier hypothesis: Oriental Medicine is received so warmly in the West because of its ideological background.

In addition, it is much easier than two hundred years ago to travel to Japan or China and learn Oriental Medicine in its original context from Japanese or Chinese experts. At least in China a vested economic interest exists to train foreigners in Chinese Medicine. Also, in the contemporary West, quite a number of writers know how to read Chinese and Japanese texts on Oriental Medicine; thus they are able to analyse and describe its theoretical foundations in ever greater detail. 
Hence, in contrast to 200 years ago, a grow ing number of translations of ancient Chinese texts have been translated and analysed in Western languages over the past two decades, strengthening the basis of an understanding of Oriental Medicine.

To conclude, medicine is an instrument developed and employed to cope with disease and to protect against early death. Still, medicine is not an ordinary instrument that retains its meaning and usefulness regardless where it is employed. When a specific medical system is transferred from one culture into another, it may lose its meaning and usefulness if it is not accompanied or met by an ideological background predisposing the minds of people in the receiving culture to acknowledge its approach as plausible. The transfer of Oriental Medicine from the Far East to Europe and America is a case in point. Prior to the 20th century, its introduction to Europe was neither accompanied nor met by an appropriate ideological context. Hence it had no chance to achieve long-term recognition and acceptance. In contrast, in the second half of the 20th century, a considerable segment of the population in Europe and in the USA had developed a world view longing for an alternative to Western medicine. This alternative was provided by Oriental Medicine which is presented in the West not in its original historical context but on the basis of concepts that have been adapted to Western expectations. The re-definition of 気 as "energy" is the most conspicuous example of this adaptation.

Clinical successes are only of secondary importance for the reception of a therapy system. Western medicine has never been more successful than today, and yet an increasing number of people in the West turn their backs on Western medicine. The reason is that their outlook on how to solve social and existential threats best has changed. $\mathrm{O}$ riental Medicine in its "Westernized" version has benefitted from these developments, and in turn benefits these people. 